\title{
Evolução do campo das dificuldades de aprendizagem específicas em Portugal: Das implicações nacionais às internacionais
}

\author{
Ana Paula Loução Martins ${ }^{a}$, Paula Marisa Fortunato Vaz ${ }^{\text {b }}$ \\ ${ }^{a}$ Centro de Investigação em Educação, Instituto de Educação, Universidade do Minho, Portugal,

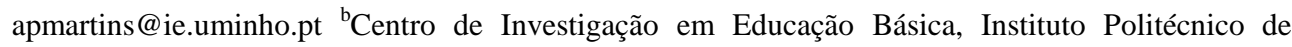 \\ Bragança, Campus de Santa Apolónia, 5300-253 Bragança, Portugal, paulavaz@ipb.pt
}

\section{Resumo}

Este artigo tem por finalidade fazer sobressair o conjunto de eventos, de perspetivas e de influências que têm promovido o aparecimento $e$ aperfeiçoamento do campo das dificuldades de aprendizagem específicas em Portugal. Começamos por traçar o historial do campo e refletir sobre a situação portuguesa, referindo e problematizando as ações do governo e dos pais ao longo dos tempos, olhando com especial atenção para a legislação portuguesa atual sobre educação inclusiva. De seguida apresentamos resultados de um estudo influenciado pelo paradigma naturalista que contou com a participação de sete Professores Doutores. Os dados foram recolhidos através de entrevistas parcialmente estruturadas, de resposta aberta, e de análise de documentos. O conhecimento adquirido relativo ao cruzamento das perspetivas sobre a evolução do campo das dificuldades de aprendizagem específicas em Portugal mostra que, segundo os participantes: a) a evolução do campo não tem sido muito visível nos últimos 40 anos; b) as razões que têm estado na origem desta evolução pouco significativa são a ausência de envolvimento governamental, a supremacia das teorias de ensino maturacionistas e construtivistas, e a existência de um padrão cultural de permissividade. Terminamos lançando o desafio de fazer emergir a importância do tema para o contexto educativo, social e político nacional e internacional.

Palavras-chave: Dificuldades-de-aprendizagem-específicas, qualitativo, investigação. 


\section{Introducão}

Desde o início do século XIX que as dificuldades de aprendizagem específicas têm vindo a intrigar e a captar o interesse de vários profissionais dos campos da medicina, psicologia e educação. A investigação tem evidenciado que a problemática das dificuldades de aprendizagem específicas é universal, ou seja, ocorre em todas as línguas, culturas e nações do mundo (Lerner, 2000). A literatura produzida na Austrália, no Canadá, na Alemanha, na Inglaterra, nos EUA, no Japão, na Holanda, na Suécia, na Finlândia, na Noruega ou em Portugal (ver em Martins, 2006, por exemplo, Bravo-Valdivieso \& Muller, 2001; Correia, 2004b; Elkins, 2001; Fonseca, 1996; Gunther, 2001; Klassen, 2002; Lundberg \& Hoien, 2001; Masayoshi, 2001; Stevens \& Werkhoven, 2001; Vianello \& Moniga, 1996; Vogel, 2001; Wedell, 2001; Wong \& Hutchinson, 2001), em conjunto com a investigação comparativa tem, igualmente, mostrado que existem muitas diferenças na forma como cada país compreende o fenómeno das dificuldades de aprendizagem específicas, na terminologia usada e no modo como a escola se organiza para responder às necessidades e características dos alunos. Adicionalmente, tem revelado que, mesmo quando a terminologia utilizada coincide, as definições conceptuais e operacionais podem ser diferentes. Tem, igualmente, revelado que, num mesmo país, existem diversas definições utilizadas em simultâneo e que há alguma similaridade na história inicial do campo em alguns destes países (Vianello \& Moniga, 1996). Em Portugal o conceito de dificuldades de aprendizagem específicas aparece, em 1984, num livro de Vítor da Fonseca intitulado Uma Introdução às Dificuldades de Aprendizagem (Correia, 2002). Passados mais de 30 anos desde a primeira edição deste livro, o termo e o conceito estão presentes na comunicação de professores, médicos, psicólogos, investigadores, alunos, pais e população em geral, bem como em publicações do Conselho Nacional de Educação ou do Ministério da Educação. Assim, neste artigo caracterizamos e analisamos as percepções de sete profisionais no que respeita à evolução do campo das dificuldades de aprendizagem específicas em Portugal.

\section{Metodologia}

\subsection{Participantes}

Este estudo contou com a participação de sete professores que lecionavam em cinco universidades portuguesas, situadas nas regiões do Norte e Centro de Portugal, cujas idades estavam compreendidas entre os 45 e os 70 anos de idade. Quatro deles eram docentes e regentes de disciplina de dificuldades de aprendizagem específicas (com denominações diferenciadas) em cursos de formação inicial ou de mestrado e dois eram membros de 
organizações ou redes nacionais e/ou internacionais relacionadas com a área. Todos tinham publicações e investigações feitas sobre o tema. Estes participantes foram intencionalmente selecionados porque se acreditava que seriam capazes de, compreensível e abrangentemente, abordar questões relacionadas com o fenómeno em estudo (Lincoln \& Guba, 1985; Patton, 2002).

\subsection{Instrumentos de recolha de dados}

Os dados foram recolhidos através de entrevistas parcialmente estruturadas, de resposta aberta, e de análise de documentos, considerando-se, desta forma, o que os participantes disseram, mas também o que tinham antes escrito. Todas as entrevistas foram gravadas e reproduzido por escrito, na íntegra, o discurso dos participantes, incluindo os silêncios, as interrupções, os risos e as entoações usadas durante as entrevistas, muitas vezes reflectindo os sentimentos e o pensamento daquilo que os participantes pretendiam transmitir. São exemplos de documentos públicos da autoria ou co-autoria dos participantes, teses de doutoramento, trabalhos no âmbito das provas de obtenção do grau de agregado, livros, artigos, brochuras e programas de disciplinas relacionados com o tema das dificuldades de aprendizagem específicas, bem como documentos pessoais. $\mathrm{O}$ acesso aos documentos públicos foi feito através de pesquisa efectuada em bases de dados das bibliotecas das universidades onde os participantes lecionavam, e os documentos privados foram gentilmente cedidos pelos participantes.

\subsection{Análise da dados}

Neste estudo utilizou-se a análise de conteúdo como técnica de tratamento da informação contida nas entrevistas e nos documentos (Bardin, 1977). Esta técnica permitiu reduzir dados, encontrar ideias padrão ou temas e fazer inferências, válidas e replicáveis, dos dados para o seu contexto (Patton, 2002). O sistema de categorias foi elaborado segundo um misto de análise dedutiva (com categorias pré-determinadas de acordo com uma referência teórica) e de análise indutiva (com categorias que emergiram dos dados), à medida que se foram lendo e relendo os dados obtidos (Miles \& Huberman, 1994; Patton, 2002). Os resultados apresentados nesta comunicação foram obtidos através da categoria denominada de "evolução do campo das dificuldades de aprendizagem específicas em Portugal". O conhecimento adquirido foi sintetizado e discutido sob a forma de cruzamento de informação dos participantes e por fim é mobilizanda a informação teórica em conclusões e recomendações, procurando-se dar voz própria à informação e ao conhecimento que se ganhou com o desenvolvimento e finalização deste projecto. 


\section{Resultados}

Os participantes neste estudo iniciaram as suas actividades profissionais nos anos 60, 70 e 80 e, de acordo com cinco deles, a evolução-vista como um processo de transformação gradual que se opera ao longo do tempo e que se substancia, nomeadamente, na alteração das características do campo das dificuldades de aprendizagem-, até 2006 não tinha sido muito visível em Portugal. Os factores que apontaram para que não tenhamos passado de um estado a outro, considerado mais avançado, foram diversos e podem ser sintetizados e caracterizados com base em três aspectos que estão, possivelmente, relacionados e recebem influências mútuas, e se caracterizam de seguida.

1. Inexistência de envolvimento governamental: Segundo três participantes a evolução pouco significativa no campo das dificuldades de aprendizagem específicas justifica-se pelo regime político não democrático que se vivia em Portugal antes da revolução de 25 de Abril de 1974 e, nos tempos mais recentes, pela ausência de uma política clara, prioritária, continuada e de qualidade. Um dos participantes refere:

Politicamente muitas coisas são vistas como algo que é temporário. Se todas as pessoas têm dificuldades e isto é mais uma; e se é mais uma não tem grande importância. Por isso, creio que não tem havido uma política continuada, diria até uma política séria, em relação a estas crianças, que representam a grande maioria dos alunos com necessidades educativas especiais. Também, os governos nunca tiveram o cuidado - e deviam tê-lo-, de produzir documentos que servissem de referência para os professores, porque [eles] são os grandes agentes [de mudança]. (Beta, E1, I[30, citado por Martins, 2006)

Adicionalmente, estes participantes, mencionam a falta de advocacia como factor impeditivo de progresso.

2. Teoria, organização e eficácia do ensino: Um dos participantes menciona a importância da ideia transmitida pelas teses maturacionistas, ao nível das práticas do ensino da leitura, de que a aparente dificuldade na aquisição de determinada capacidade académica é, apenas, um atraso de maturação: "aquilo a que eu chamo, o triunfo das teses maturacionistas da leitura: a ideia de que [ao] sujeito que comece a ter dificuldades na leitura . . . bastar-lhe-á amadurecer, ... [deixar] passar o tempo e, através de um ato mais ou menos milagroso, ele virá a aprender a ler e a escrever” (Zeta, E1, I[34, citado por Martins, 2006).

Consequentemente, a imaturidade do aluno é assumida como a maior causa das dificuldades de aprendizagem e, portanto, o acto de esperar algum tempo para que o desenvolvimento ocorra na criança, é visto como natural. A ideia difundida pelas teorias construtivistas de que os alunos devem construir o seu próprio saber é, segundo um dos participantes, igualmente popular no seio dos profissionais portugueses e impeditiva de 
progresso. São igualmente referidas, por um outro participante, ideias relacionadas com a forma como a sala de aula é organizada para dar resposta às necessidades dos alunos. Adicionalmente, um terceiro participante, considera que a falta de uma abordagem mais eficaz ao nível da intervenção específica, que é feita junto dos alunos, não tem promovido o desenvolvimento do campo das dificuldades de aprendizagem específicas.

3. Padrão cultural: Segundo dois dos participantes, algumas das características da população portuguesa, nomeadamente a permissividade, a tolerância, o desinteresse, o catolicismo, a pouca valorização da história, a pouca organização, ou a pouca valorização do que é científico, ao reflectirem-se no funcionamento da escola, impedem a evolução do campo das dificuldades de aprendizagem específicas.

Paralelamente à referência dos aspectos acima indicados, dois participantes lembram que, no entanto, o atendimento feito a alunos com necessidades educativas especiais, nomeadamente com, por exemplo, deficiência visual, auditiva, mental ou motora, tem sofrido algum progresso, chegando um deles a afirmar que em relação a estes grupos existiram muitas alterações a nível educativo. Tal foi justificado com a existência de legislação, com o seguimento das tendências que subsistem na Europa e noutros países, com a mudança, em 1974, do regime político português e com a oferta de formação especializada nas universidades portuguesas.

Referimos as razões que, segundo os participantes, têm estado na origem da evolução pouco significativa deste campo em Portugal. Segundo a literatura, internacionalmente o envolvimento governamental tem sido influente e decisivo para a fundação e a expansão do campo das dificuldades de aprendizagem específicas. Contudo, tal como se pode ver no Quadro 1, outras razões são igualmente indicadas pelos investigadores internacionais. De entre estas, salienta-se a existência de organizações de pais e de profissionais dedicadas à defesa dos interesses dos alunos, a escolha de um nome genérico que pudesse abarcar a variedade de problemas académicos que caracterizam as dificuldades de aprendizagem e que, ao mesmo tempo, fosse consensual (Ariel, 1992; Hammill, 1993; Kirk, 1981), a evolução da educação especial, a produção de investigação nas áreas da neurologia e da intervenção remediativa, o desenvolvimento da psicologia (Ariel, 1992), a aprovação de legislação que protege e apoia as crianças e os jovens em idade escolar, a existência de programas educativos ou de adaptações curriculares ao longo do percurso escolar dos alunos e a presença nas escolas de profissionais de diferentes áreas disciplinares (Hammill, 1993). 
Tabela 1. Eventos que segundo Ariel (1992) e Bender (2004) contribuiram para o desenvolvimento do campo das dificuldades de aprendizagem específicas

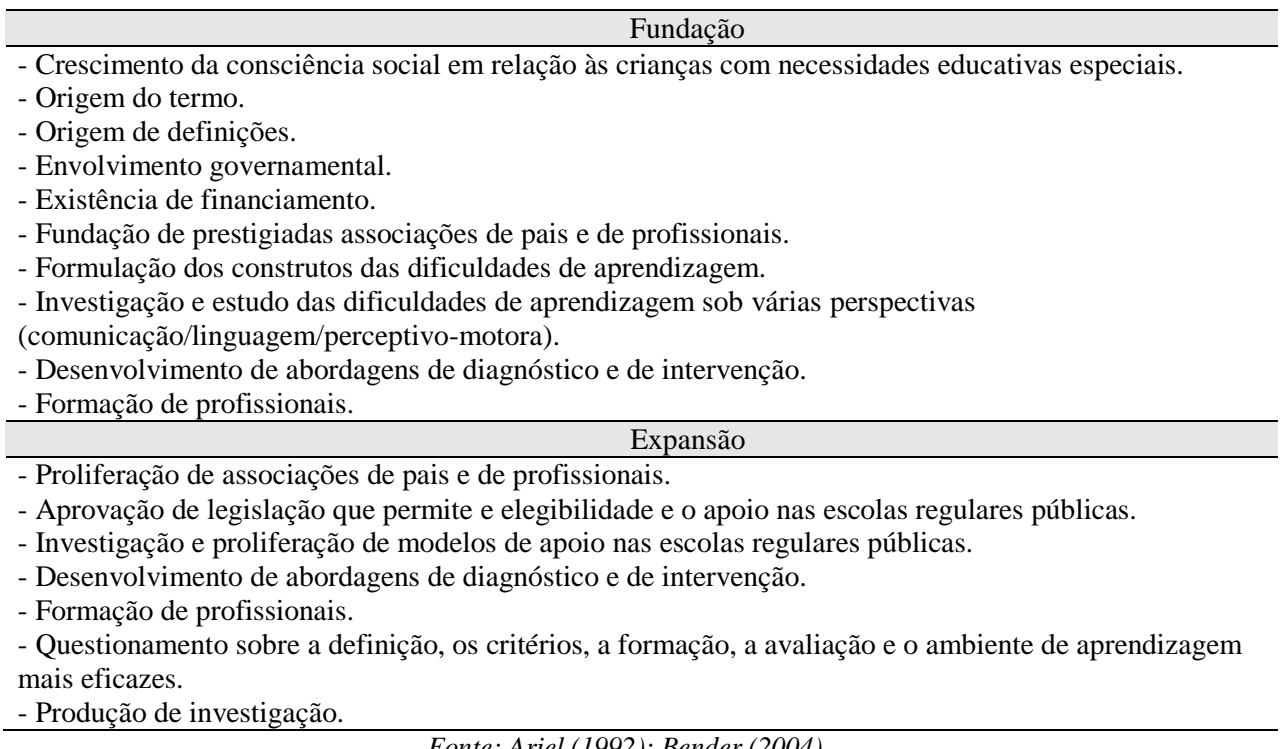
Fonte: Ariel (1992); Bender (2004)

Factores políticos, humanos e de funcionamento desempenham um papel fundamental na fundação e na expansão do campo das dificuldades de aprendizagem específcas. Olhando para o conhecimento produzido pela investigação internacional, e para as perspectivas dos participantes neste estudo, termina-se esta secção com a noção de que a fundação e o desenvolvimento do campo das dificuldades de aprendizagem específicas em Portugal depende de uma maior ação do governo e das associações de pais e de profissionais, da produção de investigação, da divulgação de informação e da existência de formação.

\section{Conclusões}

Tendo como referência o paradigma naturalista referido por Lincoln e Guba (1985), desenvolveu-se uma abordagem de investigação básica e exploratória que no final lança o desafio de fazer emergir a importância do tema para o contexto educativo, social e político, e de desenvolver um campo de investigação sobre o qual pouco se tem incidido em Portugal.

Segundo resultados do estudo, o campo das dificuldades de aprendizagem específicas em Portugal, visto através das perspectivas dos participantes, evidencia escassa progressão, devido à ausência de envolvimento governamental, à supremacia das teorias de ensino maturacionistas e construtivistas, e à existência de um padrão cultural de permissividade. 
Assim, sublinha-se como conclusão que em Portugal o campo das dificuldades de aprendizagem específicas, visto através das perspectivas dos sete participantes, é mais teórico e científico, do que político e social. É teórico e científico no sentido em que se caracteriza de certa forma pelas tentativas que estes participantes têm levado a efeito, para formar e informar sobre o fenómeno das dificuldades de aprendizagem específicas. $\mathrm{O}$ fenómeno social é aqui entendido como a ação dos membros da sociedade portuguesa, especialmente dos pais, ou seja, ações e pressões sociais feitas junto do governo, no sentido de os alunos com dificuldades de aprendizagem específicas beneficiarem de uma educação que vai ao encontro das suas necessidades. O termo político é visto como o "envolvimento governamental", na procura de estudar o estatuto e as necessidades dos alunos com dificuldades de aprendizagem específicas, de desenvolver políticas de educação adequadas que contribuam para a igualdade de oportunidades entre todos os alunos que frequentam a escola, de encorajar a implementação dos desenvolvimentos científicos sobre esta problemática, nas atividades do dia-a-dia da escola e da sociedade portuguesa. Foi unânime entre todos os participantes neste estudo que a falta de envolvimento do governo na formulação de políticas, coerentes e fundamentadas cientificamente, contribuiu ao longo dos anos para que o campo das dificuldades de aprendizagem específicas, na sua vertente de apoio aos alunos, tenha sido limitado no nosso país. Tendo por base a influência das ideias de vários investigadores internacionais (Kauffman, Hallahan, \& Lloyd, 1998; Kavale \& Forness, 1998), a leitura que se pode fazer aos resultados globais deste estudo conduz a que se sublinhe que se terá de procurar uma relação de equilíbrio entre o científico, o social e o político. Importa que esta relação maximize as oportunidades de avanço na compreensão do que são as dificuldades de aprendizagem específicas e a existência de uma educação eficaz para todos os alunos. A legislação de 2018 (Decreto-Lei 54/2018) sobre educação inclusiva poderá fomentar essa educação eficaz, ao permitir que as escolas incrementem um apoio próativo baseado na implementação de um sistema integrado de deteção precoce e progressivos níveis de intervenção.

Assim, no contexto da abordagem multinível preconizada nesta nova legislação (Decreto-Lei 54/2018), é desejável a implementação de um modelo baseado no grau de resposta dos alunos à intervenção, um modelo educativo preventivo assente no pressuposto da prevenção das dificuldades de aprendizagem específicas, sob pena de estas se agravarem e de assim conduzirem os alunos que as possuem em direção ao insucesso (Vaz, 2015). Neste contexto propõe-se um sistema de triagem universal (uma vez em cada período letivo), feita com recurso a provas de realização breve, de fácil administração e cotação, que têm o nome de provas de monitorização com base no currículo para a leitura oral (fluência da leitura) e para a compreensão da leitura (provas Maze). Procura-se com este sistema a detecção precoce dos alunos que estão em situação de risco, o estudo aprofundado destes alunos e a implementação de programas de intervenção em diferentes níveis para os mesmos, bem 
Evolução do campo das dificuldades de aprendizagem específicas em Portugal: Das implicações nacionais às internacionais

como a monitorização semanal da sua evolução (com recurso ao mesmo tipo de provas preconizadas para a triagem).

No presente artigo caraterizámos a evolução do campo das dificuldades de aprendizagem específicas em Portugal procurando conhecer o passado e o presente para melhor compreendermos e prepararmos o futuro quer ao nível escolar, quer ao nível da investigação.

\section{Referências}

Ariel, A. (1992). Education of children and adolescents with learning disabilities. New York: Merril.

Bardin, L. (1977). Análise de Conteúdo. Lisboa: Edições 70.

Bender, W. N. (2004). Learning disabilities: Characteristics, identification, and teaching strategies. Boston: Allyn and Bacon.

Correia, L. M. (2002). Identificação, avaliação e programação para alunos com dificuldades de aprendizagem: Um modelo possível. Provas de agregação no grupo disciplinar de psicopedagogia e educação especial da criança, Instituto de Estudos da Criança, Universidade do Minho, Braga, Portugal.

Erlandson, D. A., Harris, E. L., Skipper, B. L., \& Allen, S. D. (1993). Doing naturalistic inquiry. London: Sage.

Hammill, D. D. (1993). A brief look at the learning disabilities movement in the United States. Journal of Learning Disabilities, 26, 295-310.

Kavale, K. A., \& Forness, S. R. (1998). The politics of learning disabilities. Learning Disabilities Quarterly, 21, 245-273.

Kauffman, J. M., Hallahan, D. P., \& Lloyd, J. W. (1998). Politics, science, and the future of learning disabilities. Learning Disability Quarterly, 21, 276-280.

Kirk, S. A. (1981). Learning disabilities: A historical note. Academic Therapy, 17, 5-11.

Lerner, J. W. (1989). Learning disabilities: Theories, diagnosis, and teaching strategies. Boston: Houghton Mifflin.

Lincoln, Y. S., \& Guba, E. G. (1985). Naturalistic inquiry. Beverly Hill, CA: Sage.

Martins, A.P.L. (2006). Dificuldades de aprendizagem: Compreender o fenómeno a partir de sete estudos de caso. Tese de Doutoramento, Instituto de Estudos da Criança, Universidade do Minho, Braga, Portugal.

Miles, M. B., \& Huberman, M. A. (1994). Qualitative data analysis. London: Sage.

Patton, M. Q. (2002). Qualitative research \& evaluation methods (3rd ed.). London: Sage. 
Vaz, (2015). Triagem universal de alunos em risco de apresentarem Dificuldades de Aprendizagem Específicas na leitura: Um estudo quantitativo no $3 .^{\circ}$ ano do $1 .^{\circ}$ Ciclo do Ensino Básico. Tese de Doutoramento, Instituto de Educação, Universidade do Minho, Braga, Portugal.

Vianello, R., \& Moniga, S. (Eds.). (1996). Introduction: European Association for Special Education. 